IIIIIIIIIIIIIIIIIIIIIIIIIIIIIIIIIIII

Original Article

IIIIIIIIIIIIIIIIIIIIIIIIIIIIIIIIIII

\title{
Stimulation of vitellogenin gene expression by permethrin in the brown planthopper, Nilaparvata lugens (Hemiptera: Auchenorrhyncha: Delphacidae)
}

\author{
Kanjana Khaeso, ${ }^{1,2}$ Hitoshi Matsumoto, ${ }^{1}$ Yoichi Hayakawa ${ }^{1}$ and Sumio Tojo ${ }^{1, *}$ \\ ${ }^{1}$ Department of Applied Biological Sciences, Saga University, Honjyo-machi, Saga-shi, Saga 840-8502, Japan \\ ${ }^{2}$ Department of Entomology, Faculty of Agriculture, Khon Kaen University, Kohn Kaen 40330, Thailand
}

(Received July 14, 2013; Accepted March 15, 2014)

\begin{abstract}
We investigated permethrin effects on female adults of Nilaparvata lugens using a line with long wings, which initiated ovarian development one day after adult emergence. Vitellogenin gene $(V g)$ expression was significantly enhanced in the adults 1 day after topical application of $10 \mathrm{ng}$ or more of permethrin per individual at 0 -day-old adulthood. Similar triggering action of the expression was observed by application of juvenile hormone (JH) III, but such actions were blocked by application together with precocene II, an antagonist of the JH. Enhanced $\mathrm{Vg}$ expression and earlier oviposition were found in adults of the next generation when adults of the preceding generation were treated with permethrin. These results strongly indicate that permethrin functions initially to induce JH III synthesis in adults before initiating ovarian development in the females, which triggers $V g$ expression, finally rendering the treated adults with earlier oviposition, even of the next generation, relating to resurgence. ( ) Pesticide Science Society of Japan

Keywords: resurgence, permethrin, juvenile hormone, vitellogenin, wing-dimorphism, Nilaparvata lugens.
\end{abstract}

Electronic supplementary materials: The online version of this article contains supplementary materials (Supplemental Figures S1-S2), which are available at http://www.jstage.jst.go.jp/browse/jpestics/.

\section{Introduction}

One of the most serious insect pests of the rice plant is the brown planthopper, Nilaparvata lugens (Stål). This species is involved in long-distance migration overseas, ${ }^{1}$ which has been conclusively demonstrated by three-dimensional backward trajectory analysis. ${ }^{2,3)}$ The adults exhibit wing dimorphism: brachypters with short wings and macropters with long wings; the macropters show delayed reproduction, lower fecundity, and higher tolerance to starvation and dryness when compared to brachypters, and so macropters are regarded to be adaptable for migration and brachypters for sedentary life. ${ }^{4,5}$ )

One of the serious problems for control of $N$. lugens by insecticide is resurgence, and investigation has focused more on the ecological aspects of resurgence. ${ }^{6,7)}$ However, during the last decade, works have been progressing to realize the physiological mechanisms of resurgence and to induce higher fecundity of $N$. lugens by insecticide application. In most female insects, fecundity is largely reflected in the synthesis of vitellogenin $(\mathrm{Vg})$, the precursor of yolk protein, which is synthesized in the

\footnotetext{
* To whom correspondence should be addressed.

E-mail: tojos@b2.bunbun.ne.jp

Published online May 9, 2014

(c) Pesticide Science Society of Japan
}

fat body under regulation of the juvenile hormone $(\mathrm{JH})$, transported by the hemolymph to the ovary, and deposited as vitellin to be utilized for embryogenesis. ${ }^{8-10)}$

In $N$. lugens, $\mathrm{Vg}$ synthesis is also triggered by the JH. ${ }^{11,12)} \mathrm{Re}-$ cently, some insecticides such as deltamethrin, imidacloprid, and triazophos were reported as agents enhancing $\mathrm{Vg}$ and/or JH synthesis, and other physiological events relating to the syntheses of these compounds were also accumulated. ${ }^{13-16)}$ However, it remains unclear whether insecticidal agents differently affect each dimorphic animal. The present study was conducted to clarify this question.

We generated two black-colored lines of $N$. lugens, expressing specifically long-winged (BL) or short-winged adults (BS), by successive selections for the adults with these characteristics. ${ }^{17)}$ $\mathrm{JH} \mathrm{III,} \mathrm{which} \mathrm{is} \mathrm{identified} \mathrm{as} \mathrm{the} \mathrm{sole} \mathrm{JH} \mathrm{in} \mathrm{this} \mathrm{species,} \mathrm{changes}$ the titer in the hemolymph differently in the two lines. ${ }^{18)}$ Also, the timing of $\mathrm{Vg}$ synthesis differs between the two lines. ${ }^{12)} \mathrm{We}$ here examined the effects of permethrin, a pyrethroid insecticide, being topically applied in sub-lethal dosages, on $V g$ expression and other physiological traits that are different between the two lines and discuss the molecular aspects of resurgence caused by permethrin. 


\section{Materials and Methods}

\section{Chemicals}

JH III [methyl (2E,6E)-10R-(oxiranyl)-3,7,11-trimethyl-2,6dodecadienoate] and precocene II [6,7-dimethoxy-2,2-dimethylchromene] were purchased from Sigma-Aldrich, Japan, permethrin [3-phenoxybenzyl ( $1 R S, 3 R S ; 1 R S, 3 S R)-3-(2,2-$ dichlorovinyl)-2,2-dimethyl-cyclopropanecar-boxylate] and buprofezin [(Z)-2-tert-butylimino-3-isopropyl-5-phenyl-1,3,5thiadiazinan-4-one] were from Wako Pure Chemical Industries, Co., Ltd., Japan and proteinase inhibitor cocktail (EDTA free) from Nacalai Tesque, Co., Ltd., Japan. Other chemicals used for cDNA preparation were described in the section relating to the preparation.

\section{Rearing of insects}

The two pure lines of $N$. lugens have been generated by successive selections over 30 generations for the black adults expressing a specific wing form that emerged from nymphs reared at high density ${ }^{17)}$ and maintained over 150 generations in our laboratory. Nymphs of these lines were reared in cylindrical acrylresin cages (i.d., $5.4 \mathrm{~cm} \times$ height $22 \mathrm{~cm}$ ) containing about 130 rice seedlings (variety Reiho) 9-11 days after germination at high density (ca. 200 nymphs per cage) under a 16L: 8D photoperiodic regime. All experiments were conducted at $25 \pm 1^{\circ} \mathrm{C}$.

\section{Treatment of insects with chemicals}

For a toxicity test, females within $24 \mathrm{hr}$ after adult emergence were each topically applied on the abdomen with $0.1 \mu \mathrm{L}$ of acetone containing permethrin of different dosages after being anesthetized under carbon dioxide. Thirty individuals were used for one concentration, and three replications were conducted for each respective dosage. The adults treated with same dosage of permethrin were kept in a container of similar size and in a similar condition to that adopted for rearing nymphs, and the number of decreased adults were checked every day for 7 days of the adult stage.

To determine the effects of some chemicals on physiological events in the body, female adults within 1 day of emergence were topically applied on the abdomen with a chemical of the same or different concentrations dissolved in $0.1 \mu \mathrm{L}$ of acetone as mentioned above, and ten individuals were each enclosed in a separate test tube (i.d., $2.0 \mathrm{~cm} \times$ height $18 \mathrm{~cm}$ ) containing a rice seedling.

To determine the effect of chemicals on $V g$ expression in the next generation, newly ecdysed last instar nymphs or 0 -dayold females of the BL line were each topically applied with 1 or $100 \mathrm{ng}$ of permethrin dissolved in $0.1 \mu \mathrm{L}$ of acetone. For a control, $0.1 \mu \mathrm{L}$ of acetone was applied. These females were mated with untreated males in test tubes, as mentioned above, and laid eggs; the nymphs hatched were reared to adults without exposure to any insecticide.

To determine the effect of chemicals on fecundity of the next generation, 0 -day-old females of the $\mathrm{BL}$ line were each topi- cally applied with $100 \mathrm{ng}$ of permethrin or $100 \mathrm{ng}$ of JH III dissolved in $0.1 \mu \mathrm{L}$ of acetone. Nymphs derived from these adults were reared in the same condition as mentioned above. Newly emerged females $(N=5)$ of the next generation were separately reared in a test tube cage (i.d., $2.0 \mathrm{~cm} \times$ height $18 \mathrm{~cm}$ ), each containing five rice seedlings with 2 males ( 2 days old) from an untreated ancestor. The seedlings were renewed every day and checked for eggs laid by the females for 7 days.

\section{RT-PCR and quantitative PCR}

In other sets of experiment to determine the effects of chemical(s) on $V g$ expression, females within 1 day of emergence were topically applied with either chemical. One and two days after the treatment, 3 females were taken from the cage and used for extraction of RNA. Total RNA was extracted using TriPure isolation reagent (Roche $\mathrm{GmbH}$, Mannheim, Germany) according to the manufacturer's protocol. ${ }^{19)}$ The RNA was stocked at $-80^{\circ} \mathrm{C}$ until construction of a double-stand cDNA for the whole body.

Two micrograms of the total RNA was reverse transcribed with oligo (dT) primer using ReverTra Ace (Toyobo, Osaka, Japan). The cDNA was amplified with a $V g$-specific primer pair (forward, GGT CTC TGC GGT ACC TAC, and reverse, TCT GGC ACT TGG GGA CTG) that was designed by selecting highly homologous sequences in known $\mathrm{Vg}$ genes of hemimetabolous insect species by the Basic Local Alignment Search Tool (BLAST) homology search on the National Center for Biotechnology Information (NCBI) database (http://www.ncbi.nlm.nih. gov/).

To determine the relative expression of the Vg gene compared to the ribosomal protein $49 \mathrm{kDa}$ gene ( $r p 49)$, the cDNA was similarly amplified with $r p$ 49-specific primer pair (forward, CTC AGG ACA AAC TGG CGT AA, and reverse, GCA TCA TCA GCA CTTCCAAT). The reaction buffer contained $4 \mu \mathrm{L}$ of dNTP mix $(10 \mathrm{nM}), 0.5 \mu \mathrm{L}$ of Taq polymerase, $33 \mu \mathrm{L}$ of sterile water, $25 \mathrm{pmol}$ of each primer (forward and reverse), and $2.5 \mu \mathrm{L}$ of cDNA templates. The standard cycling conditions used were $2 \mathrm{~min}$ at $94^{\circ} \mathrm{C}$ followed by 40 cycles of $94^{\circ} \mathrm{C}$ for $30 \mathrm{sec}, 50^{\circ} \mathrm{C}$ for $30 \mathrm{sec}$ and $72^{\circ} \mathrm{C}$ for $30 \mathrm{sec}$.

Real-time quantitative PCR was used to determine the relative expression levels of $V g$. Quantitative PCR was carried out with $2.5 \%$ of the reverse transcription product in a $20 \mu \mathrm{L}$ reaction volume of Light Cycler FastDNA Master SYBR Green I (Roche Applied Science, Indianapolis, IN, USA) using the Light-Cycler 1.2 instrument and software (Roche Applied Science). ${ }^{19)}$

\section{Sequence analysis of DNA}

The nucleotide and deduced amino acid sequence homologies were determined by searching the GenBank database using the BLASTX algorithm. Sequences were checked for their homologies with $V g s$ of other insects using a BLAST homology search on the NCBI database (http://www.ncbi.nlm.nih.gov/). 


\section{Statistics analysis}

All statistical data were analyzed by StatView 4.0 (SAS Institute Japan Ltd., Tokyo). The Fisher's PLSD test was used to determine differences in the values between treated females and controls treated only with $0.1 \mu \mathrm{L}$ of acetone. The differences were considered significant when $p$-values were less than 0.05 .

\section{Results}

\section{Toxicity of permethrin in adult $\mathrm{N}$. lugens}

Permethrin of $1 \mathrm{ng}, 10 \mathrm{ng}, 100 \mathrm{ng}, 1 \mu \mathrm{g}$, or $10 \mu \mathrm{g}$ showed significantly higher toxicity to the short-winged BS line than to the long-winged BL line of female $N$. lugens when compared during 7 days after topical application at 0-day adulthood (Fig. 1). On a wet-weight basis, the BS line was regarded to be nearly 2 times sensitive to permethrin compared to the BL line because the adult of BS line (wet weight: $2 \mathrm{mg}$ ) was heavier by $1.2-1.4$ times than that of the BL line (1.6-1.7 mg).

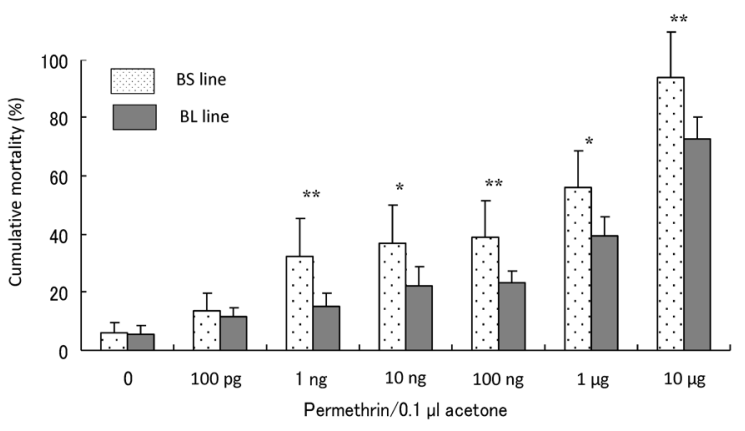

Fig. 1. Comparison of cumulative mortality of female adults of the BS and BL lines during 7 days after the 0 -day-old adults were topically applied with permethrin of different dosages as indicated in the abscissa. Significant difference between the two lines is indicated by $* 0.001 \leq p<0.05$ or $* * p<0.001$ according to Fisher's PLSD. Values are the mean \pm standard deviations $(n=30)$.

(a)

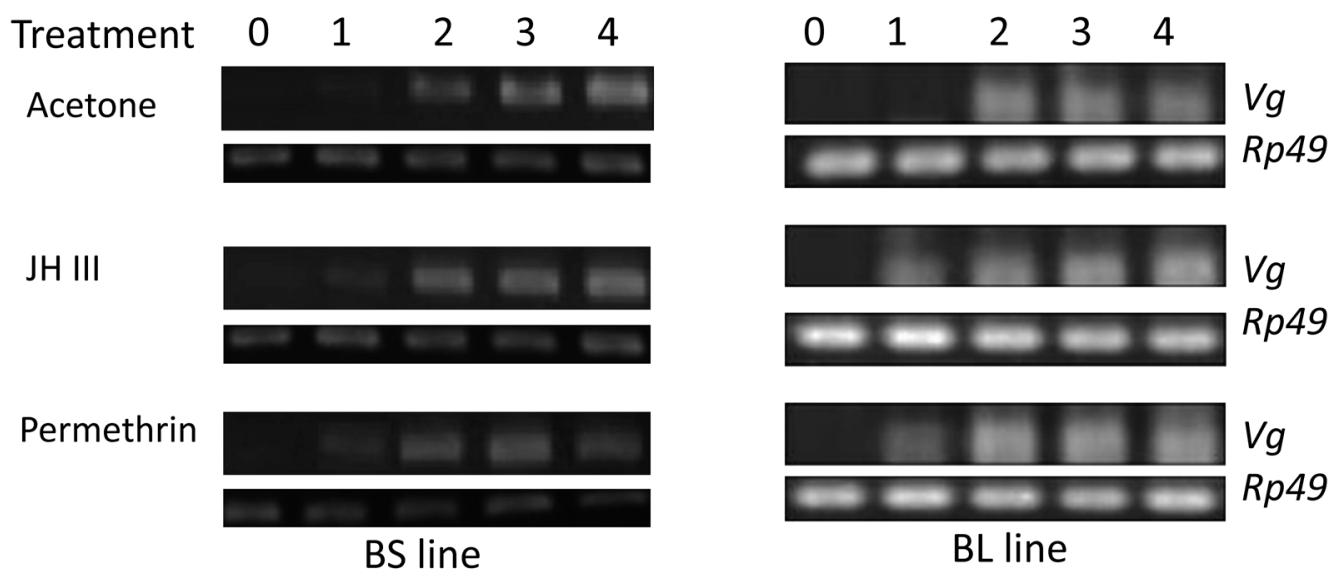

(b)

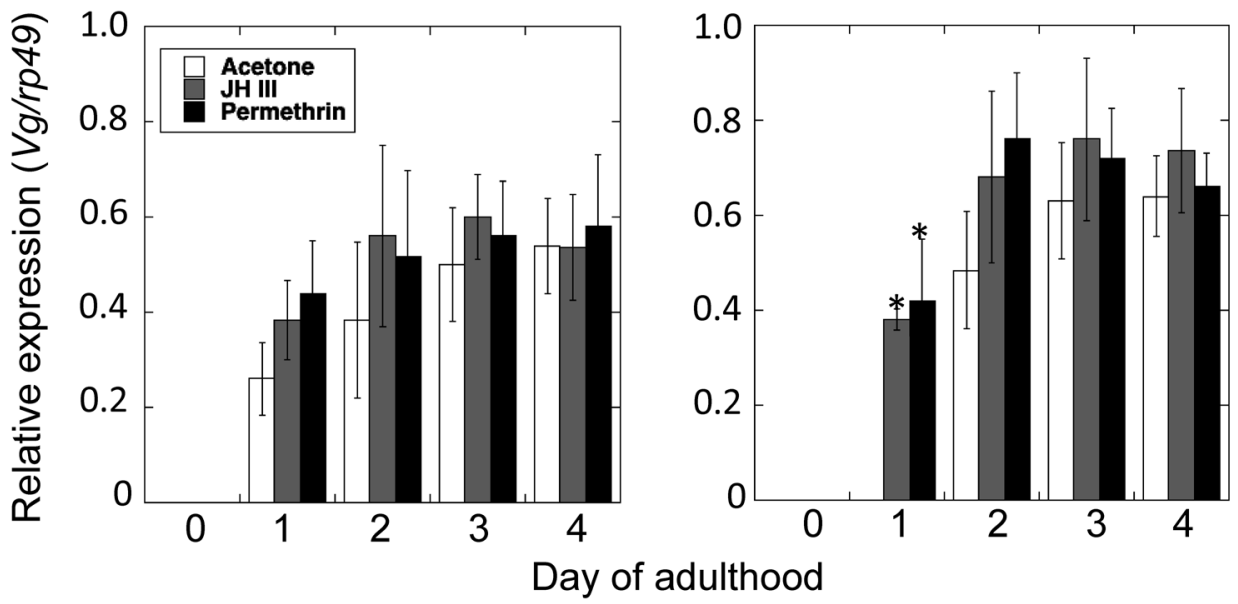

Fig. 2. Comparison of $\mathrm{Vg}$ expression profiles (a) and relative levels of the transcripts (b) between BS and BL lines of female $N$. lugens after being treated at 0 -day-old adulthood with either $100 \mathrm{ng}$ of permethrin (Permethrin), JH III (JH) dissolved in $0.1 \mu \mathrm{L}$ of acetone, or only $0.1 \mu \mathrm{L}$ of acetone (Acetone). The $V g$ expression was detected by agarose gel electrophoresis of RT-PCR products derived from total RNA. The $r p 49$ bands (bottom panels) are shown as an internal control. Significant differences from the control are indicated by the mark * $(p \leq 0.05$ according to the Fisher's PLSD test). Values are the means \pm standard deviations $(n=3)$. 


\section{Structural analysis of $\mathrm{Vg}$ cDNA of $\mathrm{N}$. lugens}

$V g$ cDNA of $N$. lugens was partially amplified by PCR using 3-day-old female adults of the BL line with $V g$-specific primers, as shown in agarose gel electrophoresis of a single transcript of ca. $400 \mathrm{bp}$ (Suppl. Fig. 1). The DNA band was amplified and found to be composed of $382 \mathrm{bp}$ (Suppl. Fig. 2). The sequence showed high homology of 91 and $88 \%$ to the mRNA of $N$. lugens $V g$ (accession Nos. JF345256.1 and AB353856.1, respectively) and 84 and $83 \%$ to the $V g$ mRNA of the small brown planthopper, Laodelphax striatella (accession Nos. KC249580.1 and KC469581.1, respectively). Therefore, we judged that the DNA band corresponds to a fragment of $\mathrm{Vg}$.

3. Comparison of $\mathrm{Vg}$ expression between two lines of $\mathrm{N}$. lugens adults

Total RNAs were extracted from the adults of these two lines from day 0 to day 4 after eclosion; during this first 1 or 2 days, they were in a pre-vitellogenic stage and then developed ovaries. ${ }^{12)} \mathrm{Vg}$ expression levels were analyzed by RT-PCR and realtime quantitative PCR. As shown in Fig. 2, a transcript of $V g$ was first detected in the BS line at 1-day adulthood and thereafter continuously synthesized, even at 4-day adulthood. In contrast, in the BL line, the $V g$ transcript was first detected in a 2-day-old adult. Thus, the BS line initiated expression of $V g 1$ day earlier than the BL line, and both lines seemed to synthesize the mRNA at high levels from the vitellogenic period onward.
4. Effects of permethrin and JH III on Vg transcript synthesis in adults

To examine the effect and function of permethrin on Vg synthesis, the female adults of both lines were topically applied with $100 \mathrm{ng}$ of permethrin or JH III dissolved in $0.1 \mu \mathrm{L}$ of acetone within 1 day after eclosion, and $V g$ expressions in the treated adults were compared with those of control adults treated only with $0.1 \mu \mathrm{L}$ of acetone for 4 days after the treatment. As shown in Fig. $2 \mathrm{a}$ and b, $V g$ mRNA first appeared in the BS line 1 day after the treatment with either $100 \mathrm{ng}$ of permethrin or JH III, as in acetone-treated control, but the levels did not significantly differ from those in the acetone-treated control. The levels in these adults under either treatment similarly increased during the following 3 days. On the other hand, in the BL line, $V g$ expressions were significantly enhanced in 1-day-old test animals treated with $100 \mathrm{ng}$ of permethrin or JH III but not in the same staged controls. Thereafter, $V g$ expression levels increased in adults treated with permethrin or JH III, but not significantly different from those of acetone-treated control. Quantitative PCR showed that $V g$ expression levels were significantly higher in the BL line than in the BS line at least one day after the chemical treatments (Fig. 2b).

5. Effects of several chemicals of different dosages on Vg transcript synthesis in adults of the BL line

$V g$ expression levels were measured in female adults of the BL line, which were topically applied with one of following chemicals, permethrin, buprofezin, JH III, or precocene II (antagonist

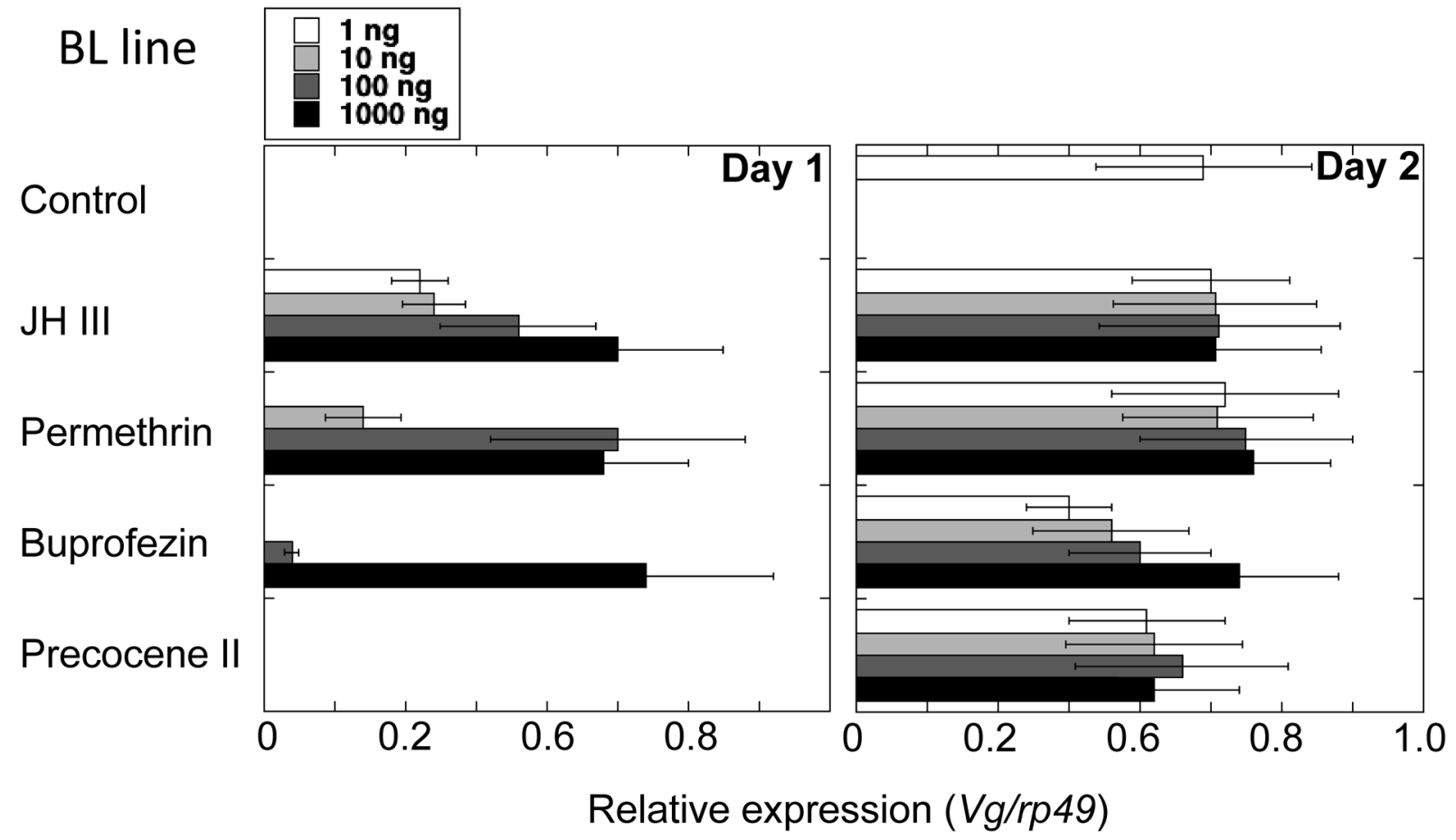

Fig. 3. Vg expression profiles in 1-day- and 2-day-old adults of female $N$. lugens of the BL line, which were topically applied at day-0 adulthood with the chemicals listed in the left side at different dosages, as indicated in the top panel. $\mathrm{Vg}$ transcripts were measured by real-time quantitative PCR. 
of $\mathrm{JH}$ ), dissolved in $0.1 \mu \mathrm{L}$ of acetone, in various dosages, i.e., 1 , 10,100 , or $1,000 \mathrm{ng}$. As shown in Fig. 3, $\mathrm{Vg}$ expression profiles in 1 -day-old adults treated with any of these chemicals mostly differed from the acetone-treated control in which $V g$ transcripts were not recognized. Significantly higher expression of $V g$ was admitted in all the samples treated with JH III of any dosage; in three samples treated with 10,100 , or 1,000 ng of permethrin; and in 2 samples treated with 100 or 1,000 ng of buprofezin, but not in those treated with precocene II of any dosage. In comparison, in 2-day-old adults, $V g$ transcripts appeared in all samples, as in the acetone-treated control, even in the adults treated with precocene II.

6. Effects of co-application of precocene II on Vg transcript synthesis in adults of the BL line

As shown in Fig. 4, $V g$ transcript expressions were totally blocked in 1-day-old adults of the BL line when either of these adults was applied with $100 \mathrm{ng}$ of precocene II at 0 -day adulthood and then $6 \mathrm{hr}$ later treated with either of $100 \mathrm{ng}$ of JH III, $100 \mathrm{ng}$ of permethrin, or $1,000 \mathrm{ng}$ of buprofezin. On the other
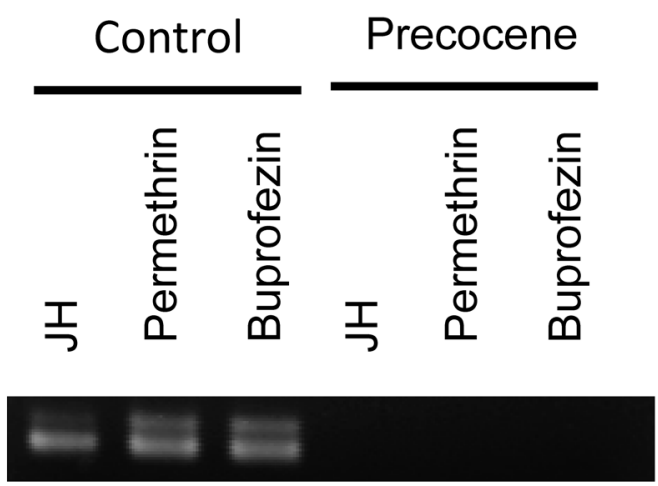

rp49

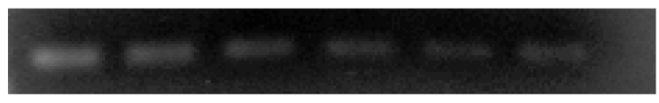

Fig. 4. $\quad V g$ expression profiles in 1-day-old adults of female N. lugens of the BL line, which were each topically applied with $100 \mathrm{ng}$ of JH III, $100 \mathrm{ng}$ of permethrin, or $1,000 \mathrm{ng}$ of buprofezin together with $100 \mathrm{ng}$ of precocene, each dissolved in $0.1 \mu \mathrm{L}$ of acetone at 0 -day-adulthood. Control adults were each treated with $0.1 \mu \mathrm{L}$ of acetone instead of precocene II.

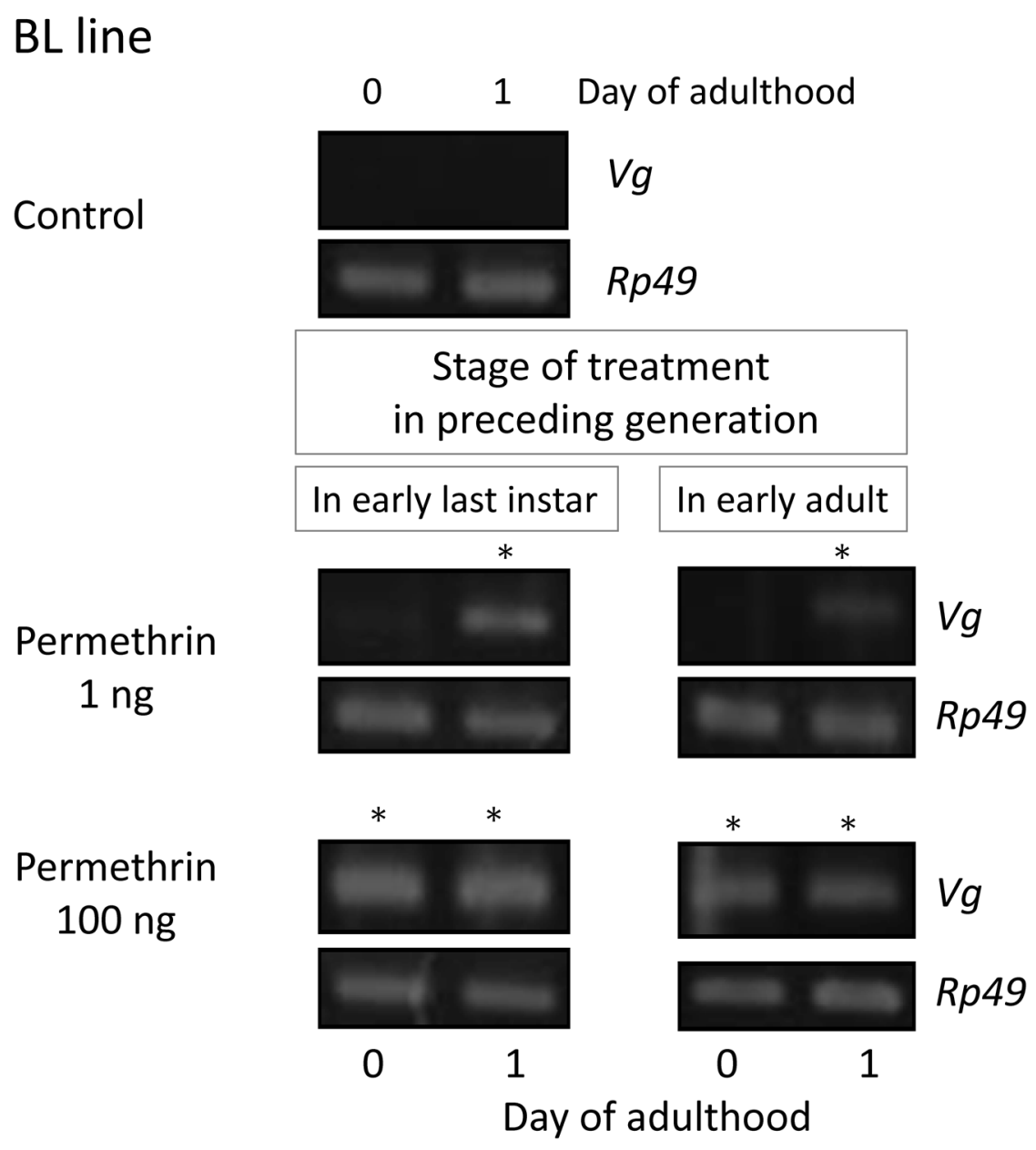

Fig. 5. $\quad V g$ expression profiles in 0-day- and 1-day-old adults of female $N$. lugens of the BL line, which were topically applied shortly after the last nymphal ecdysis (in early last instar), or day- 0 adulthood (early adult stage) with 1 or $100 \mathrm{ng}$ permethrin dissolved in $0.1 \mu \mathrm{L}$ acetone, in preceding generation. Controls were applied only with $0.1 \mu \mathrm{L}$ acetone in early adult stage of preceding generation. The $r p 49$ bands (bottom panels) are shown as internal control. 
hand, $V g$ transcripts were expressed in all 1-day-old control adults, which were treated with $0.1 \mu \mathrm{L}$ of acetone instead of precocene II.

7. Effects of permethrin treatment on $\mathrm{Vg}$ expression and ovarian development in adults of the next generation

To examine the effects of permethrin treatment in adults of the $\mathrm{BL}$ line in the next generation, each individual of the BL line was applied with permethrin shortly after the last nymphal stage or shortly after adult emergence, the adults from these treatments were mated with untreated males, and the offspring were reared to adults without any exposure to the insecticide. As shown in Fig. 5, $V g$ expression was hardly detected in 0 -day- and 1-dayold adults of the next generation from the acetone-treated control, whereas it was clearly detected in 1-day-old adults from the nymph or adults that had been treated with $1 \mathrm{ng}$ of permethrin in the preceding generation. $V g$ expression was significantly enhanced both in 0-day- and 1-day-old adults, derived from the nymph or adults treated with $100 \mathrm{ng}$ of permethrin in the preceding generation.

As shown in Fig. 6, in adults treated with $100 \mathrm{ng}$ of permethrin or JH III on 0-day-old adults in the preceding generation, egg oviposition started within 1 day after adult emergence, and nearly all eggs were laid by the third days of adulthood. In contrast, in the control adults treated only with acetone, egg oviposition started 2 days after adult eclosion, and eggs laid gradually increased toward the seventh days of adulthood.

\section{BL line}

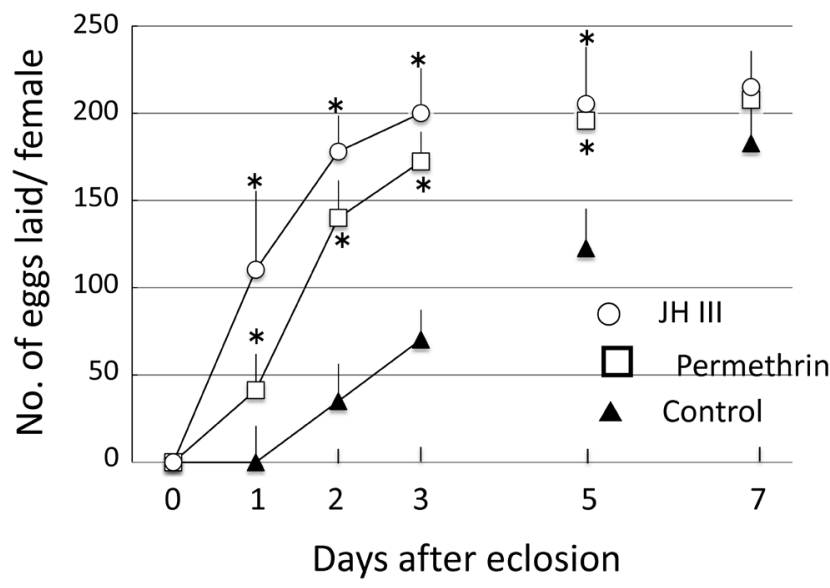

Fig. 6. Comparison of egg oviposition profiles in $N$. lugens adults of the BL line, which were topically applied at day- 0 adulthood with $100 \mathrm{ng}$ of permethrin dissolved in $0.1 \mu \mathrm{L}$ of acetone in the preceding generation and the progeny reared to adulthood without exposure to any insecticide. Controls were applied only with $0.1 \mu \mathrm{L}$ of acetone in the early adult stage of the preceding generation. Significant differences from the control are indicated by the * mark ( $p<0.05$ according to the Fisher's PLSD test). Values are the means \pm standard deviations $(n=5)$.

\section{Discussion}

1. Differences in tolerance to permethrin in the two lines of $\mathrm{N}$. lugens adults

Polyphenisms are examples of phenotypic plasticity adaptive for response to environmental cues, as typically exhibited in $N$. lugens as wingdimorphism. ${ }^{4,5)}$ We showed here that the longwinged BL line of $N$. lugens was 2 times more tolerant to permethrin on a wet-weight basis compared to the short-winged BS line when they were treated within 1 day of adult emergence (Fig. 1). Both lines have been generated from the same souse population and not exposed to any insecticides for 30 years and exposed for the first time to permethrin in this study. Such difference in the tolerance to permethrin seems to indicate longwinged adults' being inherently resistant to the insecticide compared to short-winged ones.

In $N$. lugens, macropters show higher tolerance to starvation and dryness, ${ }^{4,5)}$ the former phenomena confirmed by later studies. ${ }^{20-22)}$ A great variation in starvation period was found in long-winged adults of $N$. lugens collected in Asia, ${ }^{23)}$ indicating that macropters are more tolerant to various stressors than brachypters. Given that pesticide exposure poses a risk to organisms via a chemical stressor, the fact that the macropterous $\mathrm{BL}$ line is more tolerant to permethrin than the brachypterous BS line is reasonable. Although various physiological factors must contribute to the gain of higher tolerance to these stresses in long-winged hoppers compared to short-winged ones, the mechanism has been studied in the light of immune responses of the migratory Locust migratoria, which demonstrated that high population density induces higher tolerance to starvation, dryness, and unusual temperature in adults of phase gregaria than in those of phase solitaria. ${ }^{24)}$ A series of RNA sequencing assays revealed that gregarious locusts are significantly more tolerant to fungal biopesticide than solitary animals due to activation of prophylactical upstream modulators of immune cascades rather than downstream effectors, which enables gregarious locusts to quarantine pathogens in early infection. ${ }^{24)}$

\section{Enhancement of $\mathrm{Vg}$ transcript synthesis by permethrin}

Precocene is known to act as an anti-juvenile hormone by inhibiting the function of corpora allata to synthesize $\mathrm{JH}^{26)}$ We showed here no $V g$ transcript synthesis in 1-day-old adults of the BL line when each adult was applied with precocene II of any dosage from 1 to $1,000 \mathrm{ng}$, at 0 -day adulthood (Fig. 3). Although $100 \mathrm{ng}$ of JH III, $100 \mathrm{ng}$ of permethrin, or 1,000 ng of buprofezin was effective to enhance $V g$ expression in these experiments as presented in Fig. 3, such enhancements were blocked by a single treatment of $100 \mathrm{ng}$ of precocene II $6 \mathrm{hr}$ before the adults were exposed to either of these chemicals (Fig. 4). Therefore, it may be reasonable to assume that the mimicking action of these insecticides, such as JH III, in N. lugens is induced directly through the activation of corpora allata to synthesis $\mathrm{JH}$ III and then causes enhancement of $V g$ transcript synthesis. The two insecticides tested are quite different in chemical structure 
and function, and either chemical enhanced $V g$ transcript synthesis; however, the smallest dosage to enhance the synthesis differed between the insecticides. In order to reveal the main cause of such differences, further analysis is required.

Precocene is known to damage the ability of corpora allata to synthesize $\mathrm{JH}^{25,26)}$ We showed here that the $V g$ transcript was not expressed in 1-day-old adults of the BL line that were treated with precocene II in the dosage ranging from 1 to $1,000 \mathrm{ng}$ at 0 -day adulthood, but appeared in 2-day-old adults. This result supports that corpora allata revive the function to synthesize $\mathrm{JH}$ within 2 days of being exposed to precocene II with high concentrations of even 1,000 ng/animal (Fig. 3).

3. Effects of permethrin treatment on adults of the next generation We first showed here that the exposure of 0 -day-old adults of the BL line to $100 \mathrm{ng}$ of permethrin induced enhanced expression of the $V g$ transcript in 1-day-old adults (Fig. 2) and further demonstrated that the same treatment induced $V g$ transcript expression even in the 0 -day-old adults of the next generation and induced earlier oviposition starting from day-1 adulthood of the next generation even though the progeny was not exposed to any insecticide. Similar induction of earlier oviposition in the next generation was found when 1-day-old adults were treated with $100 \mathrm{ng}$ of JH III in the preceding generation. These facts strongly support that the enhanced $V g$ transcript expression and oviposition in adults of the next generation are due to enhanced JH III synthesis, but not by direct effect of permethrin. Enhancement of $\mathrm{Vg}$ transcript synthesis in the next generation was found even when the last instar nymphs or new adults of the preceding generation were treated with the smallest dosage of permethrin, such as $1 \mathrm{ng}$. Thus, the exposure of nymphs and adults to a very small amount of permethrin seems to change the program for JH synthesis in the next generation and induce earlier oviposition.

Several recent reports demonstrated the effects of insecticides, such as deltamethrin (pyrethroid), triazopos (organophosphorus insecticide), and imidachloprid (neonicotinoid), on the physiological affairs relating to higher reproduction when nymphs are exposed to either of these insecticides, as to induce higher contents of sugar and fat in the whole body of adults, ${ }^{13)}$ higher contents of protein and RNA in fat body and ovary protein, ${ }^{14,15)}$ and higher levels of $V g$ transcript and JH III when $N$. lugens nymphs are exposed to these insecticide. The effects are dosage-dependently stronger but differ with the kind of insecticide applied. Insecticide treatment of $N$. lugens nymphs induces not only a higher level of vitellin in female adults but also a higher level of protein in the accessory glands of male adults, which is transferred to the female via mating, so the reproductive effect of insecticides is stronger in mating pairs in which both the males and females are exposed to the insecticide. ${ }^{16)}$ Several or many novel genes, including $V g$, that are related to higher reproduction are expressed before adult eclosion after the insecticide treatment of the nymphs. ${ }^{16)}$ Thus, the effects of insecticides seem to be multiple and appear in various stages of N. lugens, as we demonstrated here as an enhancement of $V g$ transcript synthesis and fecundity in the next generation when adults of the preceding generation were exposed to permethrin.

\section{Acknowledgements}

The authors would like to express their sincere thanks to Mr. Taku Hamamoto, Ishihara Sangyou Kaisha for having maintained and supplied the lines of $N$. lugens used in the present research.

\section{References}

1) R. Kisimoto and K. Sogawa: "Insect Migration: Tracking Resources through Space and Time," ed. by V. A. Drake and A. G. Gatehouse, Cambridge University Press, New York, NY, USA. pp. 31-66, 1995.

2) A. Otuka, J. Dudhia, T. Watanabe and A. Furuno: Agric. For. Entomol. 7, 1-9 (2005).

3) A. Otuka, M. Matsumura, T. Watanabe and T. V. Dinh: Appl. Entomol. Zool. (Jpn.) 43, 527-534 (1995).

4) R. Kisimoto: Nature 178, 641-642 (1956).

5) R. Kisimoto: Bull. Shikoku Agr. Exp. Stn 13, 1-106 (in Japanese with English summary) (1965).

6) J. L. Yin, H. W. Xu, J.-C. Wu, J.-H. Hu and G.-Q. Yang: Environ. Entomol. 37, 206-212 (2008).

7) J. H. Hu, J. C. Wu, J. L. Yin and H. N. Gu: Int. J. Pest Manage 56, 23-30 (2010).

8) A. S. Raikhel and T. S. Dhadialla: Annu. Rev. Entomol. 37, 217-251 (1992).

9) G. R. Wyatt and K. G. Davey: Adv. Insect Physiol 26, 1-155 (1996).

10) L. Swevers, A. S. Raikhel, T. W. Sappington, P. Shirk and K. Iatrou: "Comprehensive Molecular Insect Science," ed. by L. I. Gilbert, K. Iatrou and S. S. Gill, Elsevier, Oxford, pp. 87-155, 2005.

11) M. Tufail, M. Naeemullah, M. Elmogy, P. N. Sharma, M. Takeda and C. Nakamura: Insect Mol. Biol. 19, 787-798 (2010).

12) M. Inada, S. Morooka, K. Itoyama and S. Tojo: Appl. Entomol. Zool. (Jpn.) 46, 545-551 (2011).

13) L. Q. Ge, J. H. Hu, J. C. Wu, G. O. Yang and H. Gu: J. Econ. Entomol. 102, 1506-1514 (2009).

14) L. Q. Ge, J. C. Wu, K. F. Zhao, Y. Chen and G. Q. Yang: Pestic. Biochem. Physiol. 98, 269-278 (2010).

15) L. Q. Ge, L. P. Wang, K. F. Zhao, J. C. Wu and L. J. Huang: Pestc. Biochem. Physiol. 98, 279-288 (2010).

16) Y. Y. Bao, B. L. Li, Z. B. Liu, J. Xue, Z. R. Zhu, J. A. Cheng and C. X. Zhang: J. Insect Physiol. 56, 1087-1094 (2010).

17) S. Morooka and S. Tojo: Appl. Entomol. Zool. (Jpn.) 27, 445-454 (1992).

18) A. G. Bertuso and S. Tojo: Appl. Entomol. Zool. (Jpn.) 37, 117-125 (2002).

19) S. Tsuzuki, M. Ochiai, H. Matsumoto, S. Kurata, A. Ohnishi and Y. Hayakawa: Sci. Rep. 210, 210 (2012).

20) S. Kusakabe and J. Hirao: Appl. Entomol. Zool. (Jpn.) 11, 369-371 (1976).

21) J. Hirao: Appl. Entomol. Zool. (Jpn.) 14, 121-122 (1979).

22) T. Ichikawa and S. Isichaikul: Proc. Assoc. Pl. Protec. Shikoku, Jpn. 29, 93-99 (1994).

23) T. Wada, K. Ito, A. Takahashi and J. Tang: Entomol. Exp. Appl. 130, 73-80 (2009).

24) Y. Wang, P. Yang, F. Cui and L. Kang: PLoS Pathog. 9, e1003102 (2013).

25) W. S. Bowers: Am. Zool. 21, 737-742 (1981).

26) M. Bownes: Annu. Rev. Entomol. 31, 507-531 (1986). 